\title{
RETRACTED ARTICLE: GelsemiumElegansBenth alkaloids extract induced cell cycle arrest resulting in anti-proliferation and pro-apoptosis effects on SMMC-7721 cells in vitro and in vivo
}

\author{
Shouye Zhao $\cdot$ Peng Liu $\cdot$ Xinyuan Wen •
}

Song Jin

Received: 2 September 2014/Accepted: 30 October 2014/Published online: 18 August 2015

(C) Springer Science+Business Media Dordrecht 2014

The Publisher and Editor retract this article in accordance with the recommendations of the Committee on Publica tion Ethics (COPE). After a thorough investigation we have strong reason to believe that the peer review process was compromised.

The original article was published online on 26 November 2014.

S. Zhao $\cdot$ P. Liu $\cdot$ X. Wen $(\varangle) \cdot$ S. Jin $(\varangle)$

Hepatobiliary Surgery Department, Affiliated Hospital of Jining

Medical College, Guhuai Road 79\#, Jining 272029, Shandong,

China

e-mail: foxandkitty@hotmail.com

S. Jin

e-mail: sjsongj@163.com

S. Zhao

e-mail: foxandkitty@126.com

P. Liu

e-mail: liuipeng@126.com 